\author{
Elavazhagan Chakkarapani \\ Marianne Thoresen \\ Xun Liu \\ Lars Walloe \\ John Dingley
}

\section{Xenon offers stable haemodynamics independent of induced hypothermia after hypoxia-ischaemia in newborn pigs}

Received: 25 April 2011

Accepted: 17 November 2011

Published online: 13 December 2011

(C) Copyright jointly held by Springer and ESICM 2011

E. Chakkarapani · M. Thoresen (区) ·

X. Liu

Department of Child Health, School

of Clinical Sciences, St Michael's Hospital, Level D, University of Bristol,

Southwell Street, BS2 8EG Bristol, UK e-mail: marianne.thoresen@bristol.ac.uk

Tel.: +44-11-73425607

Fax: +44-11-73425751

\section{J. Dingley}

Swansea Medical School, Swansea

University, Swansea, UK

M. Thoresen - L. Walloe Department of Physiology, Institute of Basic Medical Sciences, University of Oslo, Oslo, Norway
Abstract Purpose: To assess the effect of 18 hour (h) 50\% xenon (Xe) inhalation at normothermia (NT, $\left.38.5^{\circ} \mathrm{C}\right)$ or hypothermia $\left(\mathrm{HT}, 33.5^{\circ} \mathrm{C}\right)$ on mean arterial blood pressure (MABP), inotropic support and heart rate (HR) following an induced perinatal global hypoxic-ischaemic insult (HI) in newborn pigs. Methods: Newborn pigs ventilated under inhalational anaesthesia, following a 45 min HI (inhaled oxygen fraction reduced until amplitude integrated electroencephalogram was less than $7 \mu \mathrm{V})$, were randomised to three $\mathrm{Xe}$ $(n=45)(50 \%$ Xe $18 \mathrm{~h}$ with NT, HT $12 \mathrm{~h}$ or HT $24 \mathrm{~h}$ ) or three non-Xe groups $(n=53)(0 \%$ Xe with NT, HT $12 \mathrm{~h}$ or HT $24 \mathrm{~h}$ ) under otherwise identical conditions. We measured MABP and HR every minute. Hypotension (MABP $<40 \mathrm{mmHg}$ ) was treated sequentially with $2 \times 10 \mathrm{~mL} / \mathrm{kg}$ saline, dopamine, norepinephrine and hydrocortisone if required. Results: Xe maintained higher MABP during HT $(5.1 \mathrm{mmHg}$, 95\% CI 2.34, 7.89), rewarming (10.1 mmHg, 95\% CI 6.26, 13.95) and after cessation $(4.1 \mathrm{mmHg}, 95 \%$
CI 0.37, 7.84) independent of HT, inotropic support and acidosis. Xe reduced the duration of inotropic support by $12.6 \mathrm{~h}$ (95\% CI 5.5 , 19.73). Inotropic support decreased the HR reduction induced by HT from 9 to $5 \mathrm{bpm} /{ }^{\circ} \mathrm{C}$ during cooling and from $10-7$ to $4-3 \mathrm{bpm} /{ }^{\circ} \mathrm{C}$ during rewarming. There was no interaction between Xe, HT, inotropic support and acidosis. Xe during HT cleared lactate faster; $3 \mathrm{~h}$ post-HI median (IQR) values of (Xe HT) $2.8 \mathrm{mmol} / \mathrm{L}$ $(0.9,3.1)$ vs. (HT) $5.9 \mathrm{mmol} / \mathrm{L}(2.5$, 7.9), $p=0.0004$. Conclusion: $\quad \mathrm{Xe}$ maintained stable blood pressure, thereby reducing the inotropic support requirements during and after administration independently of induced HT - current neonatal encephalopathy treatment. Xe may offer haemodynamic benefits in clinical neuroprotection studies.

Keywords Xenon · Hypotension . Inotrope $\cdot$ Induced hypothermia $\cdot$ Hypoxic ischaemia $\cdot$ Pig

\section{Introduction}

In newborn infants [1-3] and pigs [4-6] with hypoxic ischaemic encephalopathy (HIE), ischaemic cardiac injury as demonstrated on histological examination manifests as persistent hypotension requiring inotropic support. In HIE clinical trials, moderate hypothermia (HT) [rectal temperature $\left(T_{\text {rec }}\right) 33-35^{\circ} \mathrm{C}$, which improves neurologic outcome, does not alter the incidence of hypotension compared to normothermia [1-3, 7].

Xenon (Xe), an anaesthetic noble gas, which offers additive neuroprotection with HT after hypoxia- 
ischaemia in rats and newborn pigs [8-10], also maintains stable arterial blood pressure and reduces heart rate (HR) in human adults during anaesthesia [11-13]. Although shortterm haemodynamic effects of Xe have been studied in adult humans and mature animal models, there are no studies with a long enough duration of Xe inhalation after hypoxia-ischaemia (HI) to match that which is suggested as being appropriate for clinical neuroprotection in humans or animals of any age. In neonates, cardiac physiology, haemodynamic response to perinatal global $\mathrm{HI}$ and recovery from $\mathrm{HI}$ are different from adults. Hypothermia, used for neuroprotection after HIE in newborns, can affect cardiac haemodynamics $[14,15]$. It is essential to know the haemodynamic effects of anaesthetic or sub-anaesthetic concentrations of Xe after HIE, and with induced HT before commencing large neuroprotection studies in newborn babies [16] where it is suggested that Xe be administered for at least $18 \mathrm{~h}$ in conjunction with cooling - the standard HIE treatment. The neuroprotection effects of the Xe and HT combination from this study have already been published [10]. Here we aimed to determine the effects of Xe and HT on blood pressure, inotropic support and HR after global HI in a newborn pig model, which has cardiovascular physiology $[17,18]$ and haemodynamic responses similar to asphyxiated newborn babies.

\section{Methods}

\section{Conduct of experiment}

This was a factorial randomised trial involving a newborn pig global HI model, which has been previously described $[4,10]$, conducted under UK Home Office regulation. In brief, after unrestrained anaesthetic induction, newborn pigs intubated with a $3.0 \mathrm{~mm}$ cuffed tracheal tube (Mallinckrodt Medical, Athlone, Ireland) were ventilated (SLE 2000 , SLE, Surrey, UK) with 1-2\% isoflurane, $70 \% \mathrm{~N}_{2} \mathrm{O}$ and $28-29 \% \mathrm{O}_{2}$ maintaining peripheral oxygen saturation $\left(\mathrm{SpO}_{2}\right)$ between 95 and $98 \%$ and the end tidal $\mathrm{CO}_{2}$ between 4.5 and $5.5 \mathrm{kPa}$. Rectal and skin temperature probes calibrated to within $\pm 0.1^{\circ} \mathrm{C}$ over a temperature range of $20-40^{\circ} \mathrm{C}$ (Criticool, MTRE, Israel) were inserted $6 \mathrm{~cm}$ into the rectum and sited on the ear lobe respectively. Umbilical arterial and venous catheters were inserted allowing continuous monitoring of mean arterial blood pressure (MABP), measurement of blood gases and infusions of maintenance fluids and drugs. Invasive arterial blood pressure was measured with a Hewlett Packard invasive blood pressure unit and single-use disposable transducers (Becton \& Dickinson, Oxford, UK) connected to the umbilical arterial catheter by a $0.9 \%$ saline-filled non-compliant tube. The pressure transducer was zeroed to the atmospheric pressure at the level of the heart in the mid-axillary line before commencing measurement.
The maximum error with the transducer due to the total effects of nonlinearity, hysteresis and sensitivity variations should then be no more than $2 \%$ of the reading or $\pm 1 \mathrm{mmHg}$, whichever is greater, over the operating range in keeping with the Association for the Advancement of Medical Instrumentation's performance standard for blood pressure transducers.

\section{Monitoring}

HR in beats per min (bpm) and MABP measured from the arterial blood pressure waveform signal (ICM software, University of Cambridge, Cambridge, UK) and $T_{\text {rec }}$ were continuously recorded every minute until $36 \mathrm{~h}$ after the HI and six hourly thereafter until the end of the experiment.

Blood gases (analysed at $37^{\circ} \mathrm{C}$ ) (Siemens Healthcare Diagnostics, Surrey, UK) and lactate (Lactate Pro ${ }^{\mathrm{TM}}$, Arkray, Inc. Kyoto. Japan) were sampled prior to, during and after HI until $72 \mathrm{~h}$, or when clinically indicated.

A single- or two-channel amplitude integrated electroencephalogram (aEEG) (Olympic or Brainz, Natus Medical Incorporated, San Carlos, USA) was continuously recorded.

Insult

The cuff of the tracheal tube was inflated and checked for any leak. Fraction of inspired oxygen $\left(\mathrm{FiO}_{2}\right)$ was reduced to $5-7 \%$ to depress the background aEEG activity to below $7 \mu \mathrm{V}$ for $45 \mathrm{~min}[4,19]$. The duration of low amplitude background activity below $7 \mu \mathrm{V}$ (LAEEG) in minutes [4] during $\mathrm{HI}, \mathrm{pH}$ and lactate at the end of $\mathrm{HI}$ were markers of insult severity in this model [20].

\section{Stabilisation and randomisation}

Pigs randomised immediately after $\mathrm{HI}$ by selecting from consecutive sealed envelopes to six treatment groups were initially resuscitated with air post-HI; $\mathrm{FiO}_{2}$ was adjusted as required via the mechanical ventilator to $30 \%$ oxygen to maintain the $\mathrm{SpO}_{2}$ between 95 and $98 \%$. After HI, inhalation anaesthesia was replaced by intravenous (iv) anaesthesia in all animals; a bolus dose of propofol $4 \mathrm{mg} /$ $\mathrm{kg}$, followed by maintenance infusions of propofol (4$12 \mathrm{mg} / \mathrm{kg} / \mathrm{h})$ and remifentanil $(20-80 \mu \mathrm{g} / \mathrm{kg} / \mathrm{h})$. This iv anaesthesia was adjusted according to HR, MABP and pigs' responsiveness.

\section{Intervention}

Thirty minutes after HI, a mixture of Xe/oxygen/nitrogen (Xe 50\%, $\mathrm{O}_{2} 30 \%, \mathrm{~N}_{2} 20 \%$ ) with concomitant decrease in 
propofol for a period of $18 \mathrm{~h}$ was delivered using a previously described closed-circuit breathing system to economise on Xe consumption [21]. Target $T_{\text {rec }}$ of $33.5^{\circ} \mathrm{C}$ was reached within $30 \mathrm{~min}$ after the HI using manual or servo-controlled whole body cooling equipment. Hypothermia was followed by rewarming to normothermia (NT, $T_{\text {rec }} 38.5 \pm 0.2^{\circ} \mathrm{C}$, which is the normal temperature for newborn pigs) [22] at a rate of $0.5^{\circ} \mathrm{C} / \mathrm{h}$.

There were three Xe treatment groups, receiving 50\% Xe in combination with NT (Xe NT, $n=12$ ), or $12 \mathrm{~h}$ HT (Xe 12 h HT, $n=18$ ), or 24 h HT (Xe 24 h HT, $n=15$ ). Xe HT denotes combined Xe $12 \mathrm{~h}$ HT and Xe $24 \mathrm{~h}$ HT groups. There were three non-Xe groups $(0 \% \mathrm{Xe})$, which were NT $(n=18)$, or HT for $12 \mathrm{~h}(12 \mathrm{~h} \mathrm{HT}, n=18)$ or 24 h (24 h HT, $n=17)$.

\section{Hypotension management}

Hypotension (MABP less than $40 \mathrm{mmHg}$ for at least $10 \mathrm{~min}$ ) [17], after confirming adequate level of anaesthesia, was managed using a formalised stepwise protocol. A bolus of two separate $10 \mathrm{~mL} / \mathrm{kg}$ of $0.9 \%$ saline was followed by dopamine $(5-20 \mu \mathrm{g} / \mathrm{kg} / \mathrm{min}$ with increments of $5 \mu \mathrm{g} / \mathrm{kg} / \mathrm{min})$. Norepinephrine $(20 \mathrm{ng}-$ $1 \mu \mathrm{g} / \mathrm{kg} / \mathrm{min}$ with increments of $20 \mathrm{ng} / \mathrm{kg} / \mathrm{min}$ ) was administered when dopamine had reached $20 \mu \mathrm{g} / \mathrm{kg} / \mathrm{min}$. Hydrocortisone $(2.5 \mathrm{mg} / \mathrm{kg} / 6 \mathrm{~h}$ or stopped earlier if the $\mathrm{MABP}$ recovered) was administered when norepinephrine reached $50 \mathrm{ng} / \mathrm{kg} / \mathrm{min}$, reflecting standard hypotension management in cooled neonates [23]. Failure to respond to the treatment within $30 \mathrm{~min}$ entailed moving to the next step of this protocol. Inotropes were reduced by $25 \%$, whenever the MABP was persistently above $40 \mathrm{mmHg}$ for more than $30 \mathrm{~min}$. Norepinephrine was weaned first followed by dopamine. After a stable 30-min period, inotropes were further weaned by $25 \%$.

\section{Recovery and autopsy}

The doses of propofol and remifentanil received by each pig were calculated during and post-Xe therapy. At the end of the treatment period in each group, iv anaesthetics were weaned. The cuffed tube was deflated after Xe inhalation. Pigs were extubated when able to breathe without support. After $72 \mathrm{~h}$ survival, pigs were reintubated and, under deep isoflurane anaesthesia, underwent terminal perfusion fixation of the brain and a full autopsy.

Statistical analysis

Data are given as mean (SD) for normally distributed variables. Skewed variables are summarised as median (range) (SAS, Cary, NC 27513; SPSS v15, Chicago,
Illinois). Effects of Xe, HT and inotropic support (as categorical variables) on MABP and HR were investigated during the following time epochs: HT period $(6-12 \mathrm{~h}$ of treatment period), rewarming period $(12-18 \mathrm{~h}$ and 24-30 h), NT (34-42 h of treatment period) and post-Xe period (18-34 h). Multiple linear regression (stepwise method) was used to identify the significant independent variables. An interaction term was included as a potential explanatory variable in this regression (as in ANOVA), but was far from significant at the 5\% level. Regression residuals were checked for normality. Regression analysis showed that there was no effect of different durations of HT with or without the presence of $50 \%$ Xe on MABP. Therefore, unless specified, the term HT includes those cooled for both 12 and $24 \mathrm{~h}$. A two tailed $p$ value less than 0.05 was considered significant.

\section{Results}

There were five main results:

1. Xe improved the MABP during cooling and rewarming independent of induced HT, inotropic support, $\mathrm{pH}$, $\mathrm{pCO}_{2}$, propofol and remifentanil doses.

2. Hypothermia $(12 \mathrm{~h} / 24 \mathrm{~h})$ with or without Xe did not affect the blood pressure.

3. Xe did not affect the HR.

4. Cooling decreased HR by $9 \mathrm{bpm} /{ }^{\circ} \mathrm{C}$ but this reduction was less $\left(5 \mathrm{bpm} /{ }^{\circ} \mathrm{C}\right)$ during inotropic support.

5. There was no interaction between the main interventions $\mathrm{Xe}$ and $\mathrm{HT}$ and other variables such as $\mathrm{pH}, \mathrm{pCO}_{2}$ and inotropic support.

There was no difference between $\mathrm{Xe}$ and non-Xe treatment groups in the weight in grams [mean (SD) 1,682 (264) vs. 1,650 (250)], age in hours [median (IQR) $18(12$, $23.5)$ vs. $(15(12,24)]$, sex (females $48 \%$ vs. $52 \%)$, insult severity (i.e. LAEEG duration in minutes) [mean (SD) 33.7 (7.66) vs. 32.1 (8.46)], lactate at the end of $\mathrm{HI}$ in millimoles per litre [mean (SD) 16 (3.26) vs. 16.5 (2.27)] or pre-HI inhalational anaesthesia duration in hours [mean (SD) 5.2 (1.44) vs. $5.2(1.88)$ ], respectively.

\section{Effects of Xe and HT on MABP}

During the $6-12 \mathrm{~h}$ epoch, when all the HT groups underwent cooling, and during rewarming (12 h HT/Xe $12 \mathrm{~h}$ HT groups), Xe significantly increased MABP by $5.1 \mathrm{mmHg}$ and $10.1 \mathrm{mmHg}$ respectively. The MABP of pigs receiving inotropes was $3.1 \mathrm{mmHg}$ and $4.2 \mathrm{mmHg}$ lower than the pigs not receiving inotropic support during 6-12 h cooling epoch and rewarming respectively (Table 1). During rewarming in $24 \mathrm{~h}$ HT/Xe $24 \mathrm{~h}$ HT 
Table 1 Effects of intervention on MABP, HR during cooling (6-12 h), rewarming, NT at the end of experiment and post-Xe period $(18-34 \mathrm{~h})$ which were independent of remifentanil, propofol, $\mathrm{pH}$ and $\mathrm{pCO}_{2}$

\begin{tabular}{|c|c|c|c|c|}
\hline Time epoch of experiment & Treatment groups & Intervention & MABP mmHg & HR beats/min \\
\hline \multirow[t]{3}{*}{$6-12 \mathrm{~h}$, during HT } & \multirow[t]{3}{*}{ All } & $\mathrm{Xe}$ & $5.1(2.34,7.89)$ & * \\
\hline & & Ino & $-3.1(-6.08,-0.12)$ & $18.0(4.57,31.32)$ \\
\hline & & HT & $*$ & $-44.6(-58.09,-31.10)$ \\
\hline \multirow[t]{3}{*}{ Rewarming (12-18 h) } & \multirow[t]{3}{*}{ NT, Xe NT, 12 h HT, Xe 12 h HT } & $\mathrm{Xe}$ & $10.1(6.26,13.95)$ & $*$ \\
\hline & & Ino & $-4.2(-8.30,-0.15)$ & $23.5(8.48,38.51)$ \\
\hline & & HT & $*$ & $-36.6(-50.83,-22.46)$ \\
\hline \multirow[t]{3}{*}{ Rewarming (24-30 h) } & \multirow[t]{3}{*}{ NT, Xe NT, 24 h HT, Xe 24 h HT } & $\mathrm{Xe}$ & * & $*$ \\
\hline & & Ino & * & $26.4(12.06,40.76)$ \\
\hline & & HT & $*$ & $-48.5(-62.17,-4.89)$ \\
\hline \multirow[t]{3}{*}{$34-42 \mathrm{~h}, \mathrm{NT}$} & \multirow[t]{3}{*}{ All } & $\mathrm{Xe}$ & * & * \\
\hline & & Ino & $*$ & $*$ \\
\hline & & HT & * & $-13.8(-25.11,-2.43)$ \\
\hline \multirow[t]{2}{*}{$18-34 \mathrm{~h}$, post-Xe } & \multirow[t]{2}{*}{ All } & $\mathrm{Xe}$ & $4.1(0.37,7.84)$ & * \\
\hline & & HT & * & $*$ \\
\hline
\end{tabular}

There was no interaction between $\mathrm{Xe}$, Ino, $\mathrm{HT}, \mathrm{pH}$ and $\mathrm{CO}_{2}$ at all these time points

$X e$ xenon, Ino inotropic support and $H T$ hypothermia as categorical variables (yes/no)

* No significant effect $(p>0.05)$

groups, initial Xe therapy/inotropes did not affect the MABP (Table 1).

There was no effect of Xe or inotropic support on the MABP during the normothermic 34-42 $\mathrm{h}$ time epoch at the end of the intervention. Hypothermia with or without Xe did not have any significant effect on MABP.

\section{Effects of Xe and HT on HR}

During the $6-12 \mathrm{~h}$ epoch, HT decreased HR by $44.6 \mathrm{bpm}$ $\left(9 \mathrm{bpm} /{ }^{\circ} \mathrm{C}\right)$. Inotropic support increased HR in the normothermic pigs by $18 \mathrm{bpm}$ and significantly reduced the bradycardic effect of HT from 9 to $5 \mathrm{bpm} /{ }^{\circ} \mathrm{C}$ (Table 1 ).

During rewarming in the $12 \mathrm{~h} \mathrm{HT/Xe} 12 \mathrm{~h}$ HT and $24 \mathrm{~h} \mathrm{HT} / \mathrm{Xe} 24 \mathrm{~h}$ HT groups, prior HT reduced the HR by $36.6 \mathrm{bpm}\left(7 \mathrm{bpm} /{ }^{\circ} \mathrm{C}\right)$ and $48.5 \mathrm{bpm}\left(10 \mathrm{bpm} /{ }^{\circ} \mathrm{C}\right)$, and inotropic support decreased the bradycardic effect of HT from 7 to $3 \mathrm{bpm} /{ }^{\circ} \mathrm{C}$ and from 10 to $4 \mathrm{bpm} /{ }^{\circ} \mathrm{C}$ compared with normothermic groups respectively (Table 1).

During the normothermic $34-42 \mathrm{~h}$ epoch, HR was $13.8 \mathrm{bpm}$ lower in the HT pigs compared to NT pigs. Inotropic support did not affect the HR. Xe did not have an independent significant effect on HR during cooling, during or after rewarming.

There was no interaction between Xe, inotropic support and HT on MABP and HR at all these time points. The effects were independent of remifentanil, propofol, $\mathrm{pH}$ and $\mathrm{pCO}_{2}$.

\section{Effect of acidosis on MABP and HR}

Xe did not affect $\mathrm{pH}$ or $\mathrm{pCO}_{2}$. Hypothermia exerted statistically significant but negligible effects on $\mathrm{pH}(-0.1)$ and $\mathrm{pCO}_{2}(+7 \mathrm{mmHg})$. However, the negligible influence of $\mathrm{pH}$ and $\mathrm{pCO}_{2}$ on MABP and HR ruled out an indirect effect of HT through ameliorating acidosis.

\section{Effect of Xe on MABP post-HI}

Figure 1a shows the difference in MABP between the Xe and non-Xe pigs, both during and after Xe inhalation. The MABP decreased during the $\mathrm{HI}$ insult and normalised after resuscitation. The Xe groups maintained a higher MABP than the non-Xe groups both during Xe inhalation (3$18 \mathrm{~h}$ ) by $4.5 \mathrm{mmHg}$ [95\% confidence interval (CI) 2.38 , 6.71] and after Xe cessation $(18-34 \mathrm{~h})$ by $4.1 \mathrm{mmHg}$ $(95 \%$ CI $0.37,7.84)$ independent of HT, acidosis, propofol and remifentanil (Table 1). A significantly higher proportion of pigs needed inotropes in the non-Xe group compared to Xe group (62.7\% vs. $37.3 \%, p=0.016$ ) (Fig. 1b). The onset and duration of inotropes in individual animals of six groups are shown in Fig. 2 (a-c, non-Xe groups; d-f, Xe groups). Xe combined with either HT or NT significantly reduced the duration of inotropic support by $12.6 \mathrm{~h}(95 \% \mathrm{CI} 5.5,19.73)$ or the need for more than one inotrope, odds ratio (OR) 0.24 (95\% CI 0.06, 0.98) and none of the Xe animals needed hydrocortisone.

\section{Lactate clearance}

Baseline blood lactate median (IQR) of $2.9 \mathrm{mmol} / \mathrm{L}$ $(2.15,3.61)$ rose to $16.7 \mathrm{mmol} / \mathrm{L}(14.8,18.3)$ at the end of HI. Lactate cleared faster in both Xe HT compared to both HT groups; median (IQR) $3 \mathrm{~h}$ post-insult lactate was $2.8 \mathrm{mmol} / \mathrm{L}(0.9,3.1)$ vs. $5.9 \mathrm{mmol} / \mathrm{L}(2.5,7.9)$ respectively, $p=0.0004$.

Cumulative (area under the curve) lactate values from the end of $\mathrm{HI}$ until $24 \mathrm{~h}$ were significantly less in the Xe 
Fig. 1 Mean difference in MABP during Xe inhalation and after Xe cessation between $\mathrm{Xe}$ (black circles) and non-Xe (grey circles) groups (a) and the proportion of pigs receiving inotropes during Xe inhalation and after Xe cessation

(b) between $\mathrm{Xe}$ (black circles) and non-Xe (grey circles) groups. HI is indicated by light grey background and the duration of Xe inhalation is indicated by grey shaded rectangle with vertical lines
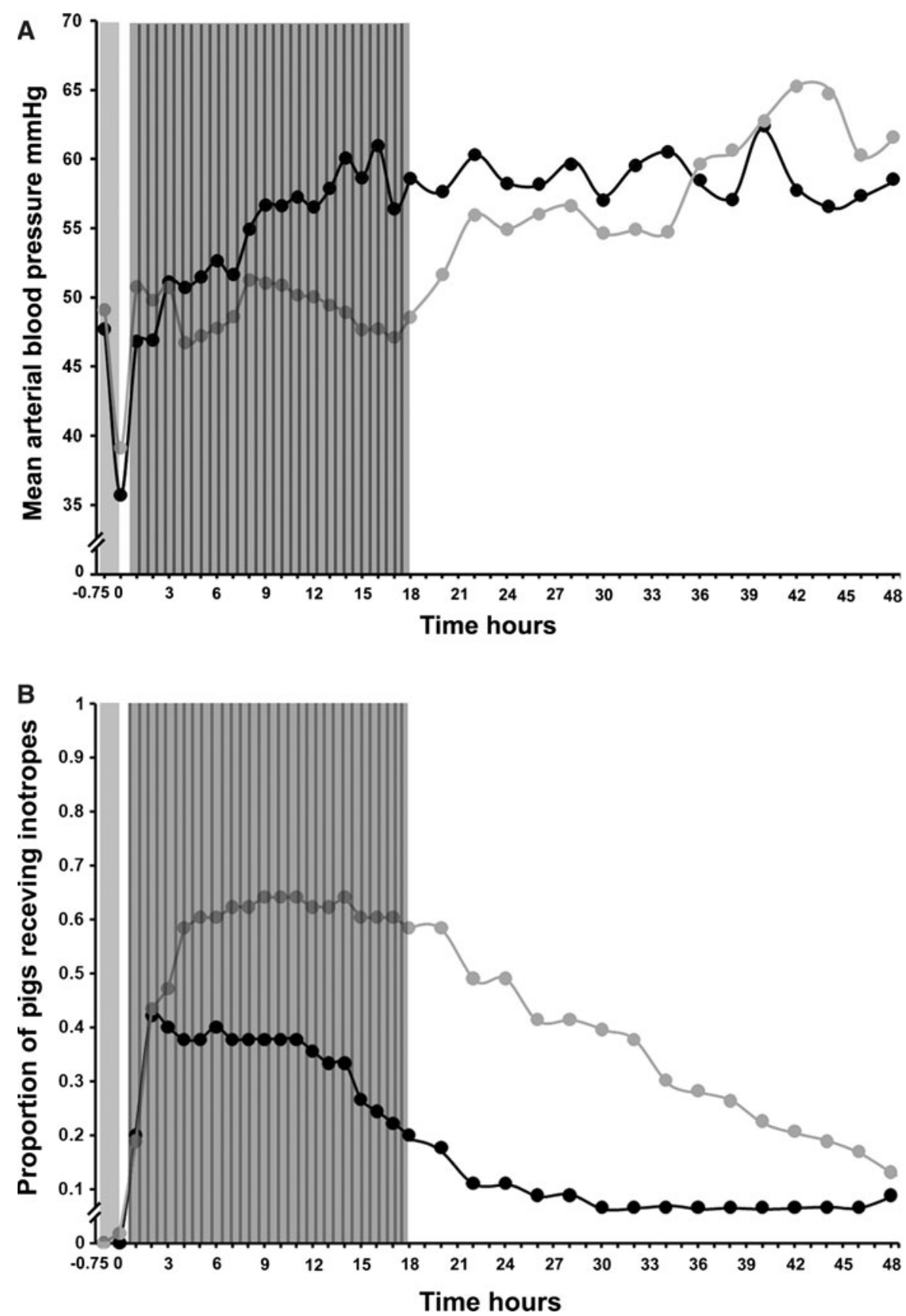

HT $57.35(15.85,176.7)$ compared to the HT groups, 74.6 inotropic support and intravenous anaesthesia. This is $(15,360), p=0.04$ (Fig 3). demonstrated by maintenance of stable blood pressure, reduction in the need for inotropic support, and rapid clearance of lactate. Cooling to $33.5^{\circ} \mathrm{C}$ with or without Xe did not have any significant independent effect on blood

\section{Discussion}

Xe inhalation improved the cardiac dysfunction in newborn pigs following a global $\mathrm{HI}$ insult; this improvement occurred during cooling, rewarming and for $16 \mathrm{~h}$ post-inhalation, independently of induced HT, acidosis, pressure. Xe did not affect the HR, while the physiological reduction in HR of HT (decrease of $9 \mathrm{bpm} /{ }^{\circ} \mathrm{C}$ ) was significantly reduced by the inotropes to $5 \mathrm{bpm} /{ }^{\circ} \mathrm{C}$.

Cardiac dysfunction following global HI presents clinically as persistent hypotension and is treated in accordance with the current neonatal practice $[23,24]$ with initial fluid 

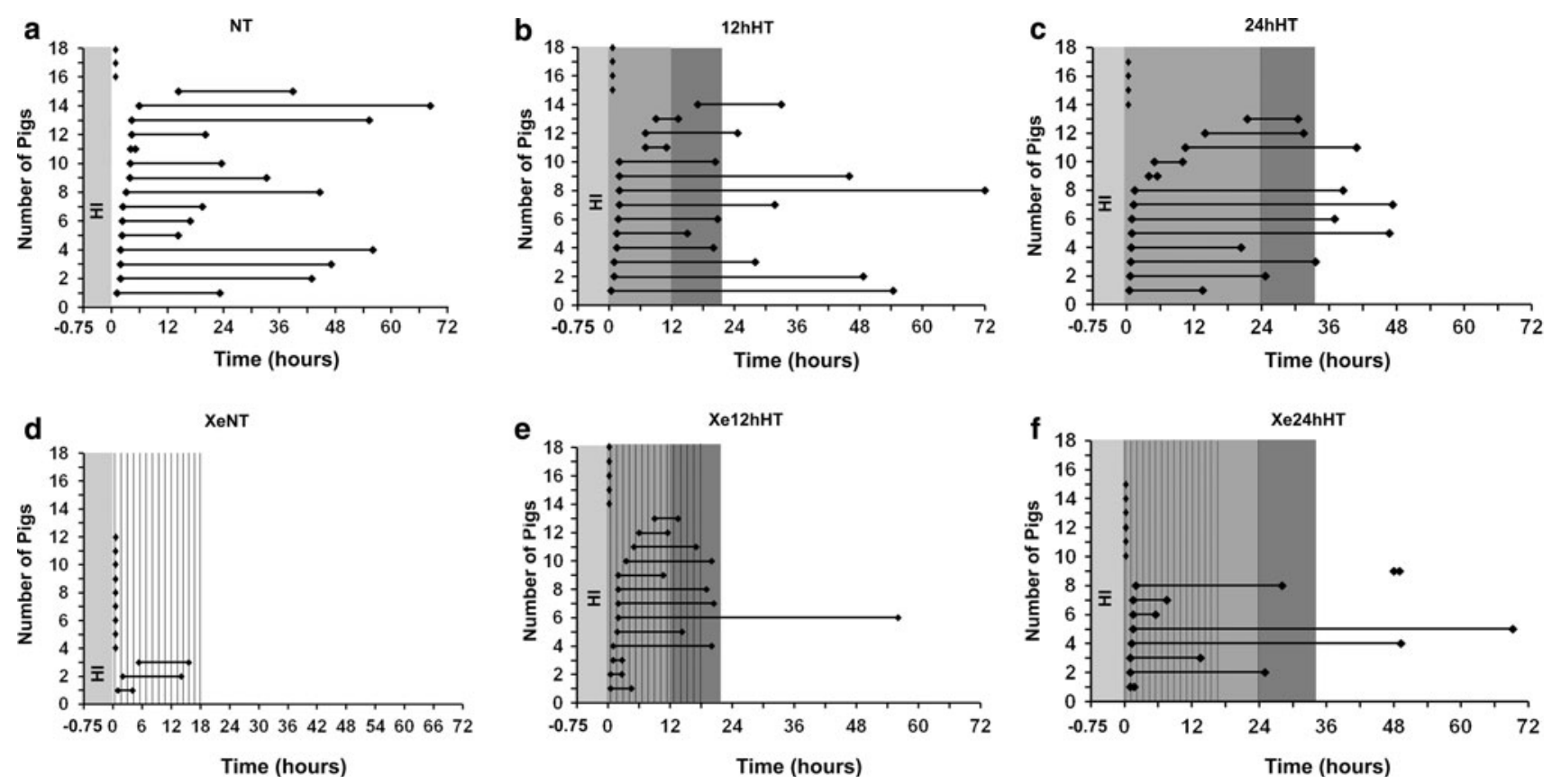

Fig. 2 Time of initiation and cessation of inotropic support in individual pigs. Three non-Xe groups are shown on the top panel $(\mathbf{a}-\mathbf{c})$ and three Xe groups are shown on the bottom panel $(\mathbf{d}-\mathbf{f})$. Pigs which did not need inotrope support are each indicated by an unconnected filled diamond. Time 0 corresponds to end of the HI.

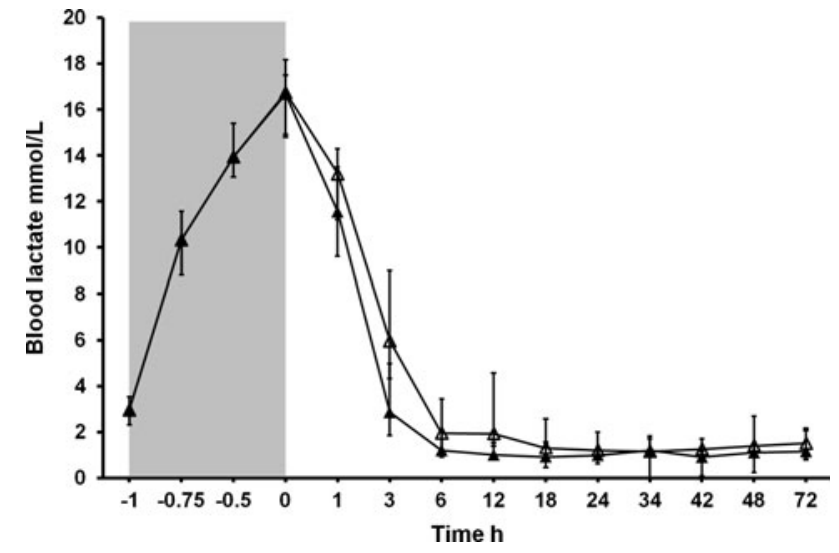

Fig. 3 Blood lactate $(\mathrm{mmol} / \mathrm{L})$ in the combined HT group $(12 \mathrm{~h}$

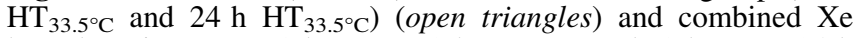
hypothermia group $\left(18 \mathrm{~h} \mathrm{Xe} \mathrm{X}_{50 \%} 12 \mathrm{~h} \mathrm{HT}_{33.5^{\circ} \mathrm{C}}\right.$ and $18 \mathrm{~h} \mathrm{Xe} \mathrm{X}_{50 \%} 24 \mathrm{~h}$ $\mathrm{HT}_{33.5^{\circ} \mathrm{C}}$ ) (filled triangles). Time -1 corresponds to baseline and time -0.75 until 0 corresponds to $\mathrm{HI}$ insult (grey box)

boluses followed by inotropic support and corticosteroids. $\mathrm{Xe}_{60 \%}$ anaesthesia for approximately $2 \mathrm{~h}$ in adults with no cardiovascular risk compared to isoflurane/nitrous oxide reduced the use of inotropes [13]. There are no similar data available either in asphyxiated neonates with cardiac dysfunction, given a prolonged duration of sub-anaesthetic $50 \% \mathrm{Xe}$, or where Xe was combined with induced HT, which is now standard HIE treatment. We followed a
Light grey boxes indicate $45 \mathrm{~min}$ of $\mathrm{HI}$ insult, medium grey boxes indicate HT, dark grey boxes indicate rewarming and vertical lines indicate Xe inhalation (linked filled diamonds indicate the duration of inotropic support)

protocolised neonatal approach in commencing treatment for persistent hypotension and weaning the inotropes in all animals. This eliminated any likelihood of overestimating the duration of inotropic support in non-Xe animals. Pigs receiving inotropic support maintained MABP lower than that of pigs not receiving inotropic support indicating that our protocol of initiation and weaning of inotropic support did maintain the MABP in the target range. Xe groups maintained the MABP within the normal range rather than inflating the MABP and hence the difference in MABP between Xe and non-Xe groups reflects a genuine improvement in cardiac function. $\mathrm{Xe}_{50 \%}$ maintained a stable MABP, $5.1 \mathrm{mmHg}$ higher than pigs that did not receive Xe independently of induced HT, propofol and remifentanil; this accounted for the reduction in the duration of inotropic support. A higher MABP has been reported in pigs anaesthetised with $\mathrm{Xe}_{50 \%}$ [25] and in adults both with and without coronary artery disease undergoing elective non-cardiac surgery under NT $[13,26]$.

The precise mechanism by which MABP is maintained is not clear. $\mathrm{Xe}_{60 \%}$ has been associated with better left ventricular performance [26] and systolic function [27] in patients with moderate cardiovascular risk [26] and ischaemic heart disease [27], respectively. Other possible mechanisms for maintaining stable MABP may be due to the preservation of the systemic vascular resistance and myocardial contractility following inhalation of $\mathrm{Xe}_{50-70 \%}$ in pigs [25], $\mathrm{Xe}_{63 \%}$ in dogs [28], and $\mathrm{Xe}_{15-53 \%}$ in humans 
who underwent coronary artery bypass grafts [29]. This could explain Xe's ability to maintain MABP $10.1 \mathrm{mmHg}$ higher during rewarming, when the systemic vascular resistance is likely to fall [30]. Systemic vascular resistance has been shown to increase with $\mathrm{Xe}_{50-60 \%}$ in myopathic hearts, associated with increase in the left ventricle isovolumetric relaxation time constant [31], which can occur in cardiac impairment post-asphyxia.

Xe's ability to counteract hypotension may account for rapid lactate clearance by maintaining better tissue perfusion. Xe demonstrated a declining 'persistent effect' on MABP by maintaining higher blood pressure, hence reducing the duration of inotropic support for $16 \mathrm{~h}$ after cessation of Xe delivery. The precise mechanism behind Xe's long-term stabilising effect on blood pressure is not known. The global HI insult in our model results in multiple sub-endocardial ischaemic lesions [5]. $\mathrm{Xe}_{70 \%}$ commenced during early reperfusion $(15 \mathrm{~min})$ following coronary artery occlusion in rabbits reduced the infarct size [32]. In our study, $18 \mathrm{~h} \mathrm{Xe} \mathrm{X}_{50 \%}$ commenced within 30 min of HI may protect the heart by improving the contractility of the ischaemic myocardium.

Core temperature reduction by $5^{\circ} \mathrm{C}$ did not have any independent significant hypotensive effect similar to the neonatal clinical trials $[2,3]$ of whole body cooling, where core temperature was reduced by $3.5^{\circ} \mathrm{C}$. Hypothermia decreased the HR by reducing metabolic rate [30]. Chronotropic effect of inotropes altered the intensity of HR reduction by HT, thereby invalidating the use of HR as a stress marker. Hypothermic groups continued to maintain a lower HR compared with normothermics even after rewarming, implying a persistent effect on metabolism. Xe did not alter the effect of HT in reducing the HR. In adult studies, $\mathrm{Xe}_{60 \%}$ has been shown to reduce the HR by the end of anaesthesia [13] like other inhalation anaesthetics. The lack of Xe's effect on HR might be due to the large rate reduction effect of HT, where the core temperature was reduced by $5^{\circ} \mathrm{C}$ and $50 \%$ Xe being less than half the minimal anaesthetic concentration (MAC) value in pigs. There was no interaction between HT, Xe, inotropic support and acidosis. This excludes the indirect cardiac effect from optimal $\mathrm{pH}$.

There were certain limitations to our study. Objective measures of assessing anaesthetic depth like bispectral index, though valid during HT [33], could not be used as the pigs' EEG showed effects of recovery from global HI with varied levels of depression; also bispectral index is unreliable with Xe [34]. Hence, we relied on total dose of anaesthetics. $\mathrm{Xe}_{50 \%}$ was commenced at $30 \mathrm{~min}$ after $\mathrm{HI}$ along with remifentanil, while propofol was reduced/ stopped. Although propofol is not routinely used in newborns, animal legislation demands deep levels of sedation influencing our choice of drugs. Also, from a design point of view, those without Xe needed an anaesthetic, hence all animals received propofol and remifentanil. The inevitable delay before onset of Xe and necessary use of sedatives like morphine in clinical situations may alter the haemodynamic findings.

In conclusion, after global $\mathrm{HI}$ in newborn pigs, $18 \mathrm{~h}$ $\mathrm{Xe}_{50 \%}$ independently of induced HT, acidosis, intravenous anaesthesia maintained a stable MABP, thereby reducing the duration of inotropic support and expediting the clearance of lactate. This stable haemodynamic effect of Xe persisted long $(16 \mathrm{~h})$ after cessation of Xe.

\section{References}

1. Gluckman PD, Wyatt JS, Azzopardi D, Ballard R, Edwards AD, Ferriero DM, Polin RA, Robertson CM, Thoresen M, Whitelaw A, Gunn AJ (2005) Selective head cooling with mild systemic hypothermia after neonatal encephalopathy: multicentre randomised trial. Lancet 365:663-670

2. Shankaran S, Laptook AR, Ehrenkranz RA, Tyson JE, McDonald SA, Donovan EF, Fanaroff AA, Poole WK, Wright LL, Higgins RD, Finer NN, Carlo WA, Duara S, Oh W, Cotten CM, Stevenson DK, Stoll BJ, Lemons JA, Guillet R, Jobe AH (2005) Whole-body hypothermia for neonates with hypoxicischemic encephalopathy. N Engl J Med 353:1574-1584
3. Azzopardi DV, Strohm B, Edwards AD, Dyet L, Halliday HL, Juszczak E, Kapellou O, Levene M, Marlow N, Porter E, Thoresen M, Whitelaw A, Brocklehurst P (2009) Moderate hypothermia to treat perinatal asphyxial encephalopathy. N Engl J Med 361:1349-1358

4. Thoresen M, Haaland K, Loberg EM, Whitelaw A, Apricena F, Hanko E, Steen PA (1996) A piglet survival model of posthypoxic encephalopathy. Pediatr Res 40:738-748

5. Haaland K, Loberg EM, Steen PA, Satas S, Thoresen M (1997) The effect of mild post-hypoxic hypothermia on organ pathology in a piglet survival model of global hypoxia. Prenat Neonat Med 2:329-337
6. Liu X, Tooley J, Loberg EM, Suleiman MS, Thoresen M (2011) Immediate hypothermia reduces cardiac troponin I after hypoxic-ischemic encephalopathy in newborn pigs. Pediatr Res 70:352-356

7. Battin MR, Thoresen M, Robinson E, Polin RA, Edwards AD, Gunn AJ (2009) Does head cooling with mild systemic hypothermia affect requirement for blood pressure support? Pediatrics 123:1031-1036

8. Thoresen M, Hobbs CE, Wood T, Chakkarapani E, Dingley J (2009) Cooling combined with immediate or delayed xenon inhalation provides equivalent long-term neuroprotection after neonatal hypoxia-ischemia. J Cereb Blood Flow Metab 29:707-714 
9. Hobbs C, Thoresen M, Tucker A, Aquilina K, Chakkarapani E, Dingley J (2008) Xenon and hypothermia combine additively, offering long-term functional and histopathologic neuroprotection after neonatal hypoxia/ ischemia. Stroke 39:1307-1313

10. Chakkarapani E, Dingley J, Liu X, Hoque N, Aquilina K, Porter $\mathrm{H}$, Thoresen M (2010) Xenon enhances hypothermic neuroprotection in asphyxiated newborn pigs. Ann Neurol 68:330-341

11. Boomsma F, Rupreht J, Man in't Veld AJ, de Jong FH, Dzoljic M, Lachmann B (1990) Haemodynamic and neurohumoral effects of xenon anaesthesia. A comparison with nitrous oxide. Anaesthesia 45:273-278

12. Lachmann B, Armbruster S, Schairer W, Landstra M, Trouwborst A, Van Daal GJ, Kusuma A, Erdmann W (1990) Safety and efficacy of xenon in routine use as an inhalational anaesthetic. Lancet 335:1413-1415

13. Rossaint R, Reyle-Hahn M, Schulte Am Esch J, Scholz J, Scherpereel P, Vallet B, Giunta F, Del Turco M, Erdmann W, Tenbrinck R, Hammerle AF, Nagele P (2003) Multicenter randomized comparison of the efficacy and safety of xenon and isoflurane in patients undergoing elective surgery. Anesthesiology 98:6-13

14. Thoresen M, Whitelaw A (2000) Cardiovascular changes during mild therapeutic hypothermia and rewarming in infants with hypoxic-ischemic encephalopathy. Pediatrics 106:92-99

15. Fugelseth D, Satas S, Steen PA, Thoresen M (2003) Cardiac output, pulmonary artery pressure, and patent ductus arteriosus during therapeutic cooling after global hypoxia-ischaemia. Arch Dis Child 88:F223-F228

16. Thoresen M (2011) The cool xenon study. Available from http://www.controlled-trials.com/ ISRCTN75602528. Accessed 11 Nov 2011

17. Haaland K, Karlsson B, Skovlund E, Lagercrantz H, Thoresen M (1995) Postnatal development of the cerebral blood flow velocity response to changes in $\mathrm{CO}_{2}$ and mean arterial blood pressure in the piglet. Acta Paediatr 84:1414-1420
18. Fugelseth D, Satas S, Runde M, Haga P, Thoresen M (1999) Cardiac function and morphology studied by twodimensional Doppler echocardiography in unsedated newborn pigs. Exp Physiol 84:69-78

19. Tooley JR, Satas S, Porter H, Silver IA Thoresen M (2003) Head cooling with mild systemic hypothermia in anesthetized piglets is neuroprotective. Ann Neurol 53:65-72

20. Haaland K, Loberg EM, Steen PA, Thoresen M (1997) Posthypoxic hypothermia in newborn piglets. Pediatr Res 41:505-512

21. Chakkarapani E, Thoresen M, Hobbs CE, Aquilina K, Liu X, Dingley J (2009) A closed-circuit neonatal xenon delivery system: a technical and practical neuroprotection feasibility study in newborn pigs. Anesth Analg 109:451-460

22. Tuchsherer M, Puppe B, Tuchsherer A, Tiemann U (2000) Early identification of neonates at risk: traits of newborn piglets with respect to survival. Thenogenology 54:371-388

23. TOBY study group (2010) Cardiovascular support. In: TOBY study handbook, phase 2. National Perinatal Epidemiology Unit, Oxford, p 16. Available via http://www.npeu.ox.ac.uk/files/ downloads/toby/TOBY-HandbookPhase-2.pdf. Accessed 28 Oct 2011

24. Subhedar NV (2003) Treatment of hypotension in newborns. Semin Neonatol 8:413-423

25. Marx T, Froeba G, Wagner D, Baeder S, Goertz A, Georgieff M (1997) Effects on haemodynamics and catecholamine release of xenon anaesthesia compared with total iv anaesthesia in the pig. Br J Anaesth 78:326-327

26. Baumert JH, Hein M, Hecker KE, Satlow S, Neef P, Rossaint R (2008) Xenon or propofol anaesthesia for patients at cardiovascular risk in noncardiac surgery. Br J Anaesth 100:605-611
27. Goto T, Hanne P, Ishiguro Y, Ichinose F, Niimi Y, Morita S (2004) Cardiovascular effects of xenon and nitrous oxide in patients during fentanyl-midazolam anaesthesia. Anaesthesia 59:1178-1183

28. Francis RC, Reyle-Hahn MS, Hohne C, Klein A, Theruvath I, Donaubauer B, Busch T, Boemke W (2008) The haemodynamic and catecholamine response to xenon/remifentanil anaesthesia in Beagle dogs. Lab Anim 42:338-349

29. Dingley J, King R, Hughes L, Terblanche C, Mahon S, Hepp M, Youhana A, Watkins A (2001) Exploration of xenon as a potential cardiostable sedative: a comparison with propofol after cardiac surgery. Anaesthesia 56:829-835

30. Thoresen M (2008) Supportive care during neuroprotective hypothermia in the term newborn: adverse effects and their prevention. Clin Perinatol 35:749-763, vii

31. Hettrick DA, Pagel PS, Kersten JR, Tessmer JP, Bosnjak ZJ, Georgieff M, Warltier DC (1998) Cardiovascular effects of xenon in isofluraneanesthetized dogs with dilated cardiomyopathy. Anesthesiology 89:1166-1173

32. Preckel B, Mullenheim J, Moloschavij A, Thamer V, Schlack W (2000) Xenon administration during early reperfusion reduces infarct size after regional ischemia in the rabbit heart in vivo. Anesth Analg 91:1327-1332

33. Seder DB, Fraser GL, Robbins T, Libby L, Riker RR (2010) The bispectral index and suppression ratio are very early predictors of neurological outcome during therapeutic hypothermia after cardiac arrest. Intensive Care Med 36:281-288

34. Goto T, Nakata Y, Saito H, Ishiguro Y, Niimi Y, Suwa K, Morita S (2000) Bispectral analysis of the electroencephalogram does not predict responsiveness to verbal command in patients emerging from xenon anaesthesia. Br J Anaesth 85:359-363 